\title{
Playful learning in higher education: developing a signature pedagogy
}

Increased focus on quantifiable performance and assessment in higher education is creating a learning culture characterized by fear of failing, avoidance of risk, and extrinsic goal-oriented behaviours. In this article, we explore possibilities of a more playful approach to teaching and learning in higher education through the metaphor of the 'magic circle'. This approach stimulates intrinsic motivation and educational drive, creates safe spaces for academic experimentation and exploration, and promotes reflective risk-taking, ideation and participation in education. We present a model of playful learning, drawing on notions of signature pedagogies, field literature, and two qualitative studies on learner conceptions of enjoyment and reasons for disengagement. We highlight the potential of this approach to invite a different mind-set and environment, providing a formative space in which failure is not only encouraged, but a necessary part of the learning paradigm.

Keywords: play; higher education; playful learning; magic circle; failure; signature pedagogy

\section{Introduction}

Throughout much of Europe and beyond, there is a growing commercialisation of higher education, with a growing focus on metrics to measure the performance of students, academics, and institutions (Ordorika \& Lloyd, 2015). The sector is increasingly competitive as universities embrace neoliberal ideas of marketization and the associated discourses of efficiency and effectiveness (Brown, 2011).

This emergence of 'the corporate university' or 'the knowledge factory' (Nixon, 2008, p. 22) promotes teaching to the test, reproduction of information, criteria-based assessment, and clear quantifiable outcomes. Rather than supporting the values accentuated as driving higher-order thinking and doing (Dettmer, 2005) or the virtues at the base of moral practice of academics (Nixon, 2008; Nørgård, Smedegaard, \& Bengtsen, 2016). Instead, these values and virtues are stigmatised as risky, 
unproductive, and too fuzzy. Learner engagement and satisfaction have become key performance indicators (e.g. the US National Survey of Student Engagement and the UK Student Satisfaction Survey), despite evidence that students and staff do not share understandings of the value of such metrics (Bennett \& Kane, 2014; Frankham, 2015). This pressure on meeting the demands of external metrics inevitably affects institutional cultures, academic practices, and learner experiences, and the increasingly performative culture of higher education creates an assessment-driven environment focused on goaloriented behaviours (Ball, 2015), characterized by avoidance of risk and fear of failure.

To counter this, we have recently witnessed an emergence of so-called gameful approaches in higher education, including the use of educational games, and gamification techniques. These are used to support student engagement, but too often focus primarily on outcomes, competition, and extrinsic rewards, and thus, in effect, echoing the performative culture of the sector. In this article we argue that while gameful approaches may be a useful technique to enhance engagement, it is the deeper playful underpinning and provision of opportunities to learn from failure that are at the heart of playful learning in higher education.

Drawing on key literature in the field, and two research studies, we develop the notion of a signature pedagogy of playful learning in higher education to consider the possibilities of an educational system that recognises the importance of openness, curiosity, risk-taking and failure in learning. As a theoretical lens, we use the metaphor of the 'magic circle' (Huizinga, 1955; Salen \& Zimmerman, 2004), coupled with the 'lusory attitude' (Suits, 1978) that is essential for meaningful activity within a playful space. Finally, we highlight the potential of this signature pedagogy of playful learning to invite a different mind-set and environment, providing a more formative pedagogical space in which open-endedness (Nørgård \& Paaskesen, 2016), virtuous academic 
citizenship (Nørgård \& Bengtsen, 2016), and ideational learning (Dettmer, 2005) are central.

\section{Gameful approaches in Higher Education}

In recent years, gameful techniques, such as gamification (using game mechanics in non-game contexts) or educational games (using games to teach), are increasingly used in higher education, commonly with an aim of increasing learner engagement, motivation, or enjoyment (e.g. DuBravac, 2012; Hemmi, Narumi-Munro, Alexander, Parker, \& Yamauchi, 2014; Mayer, Warmelink, \& Bekebrede, 2013). Many studies show that the outcomes of gameful approaches in education are positive, particularly in terms of (short-term) increased motivation and engagement in the learning tasks (Boyle et al., 2016). However, many gameful applications focus on extrinsic motivational drivers leading to changes in behaviour; there is little evidence that these techniques foster lasting enjoyment or deep learning. The use of extrinsic motivational drivers may actually diminish intrinsic motivation in the long term (Deci, Koestner, \& Ryan, 2001), which is detrimental to learning. Furthermore, research highlights negative aspects of these approaches, including cost and perceived appropriateness (Whitton, 2011), and a tendency for students to manipulate or 'game' points-based incentive systems (Baker et al., 2008).

As a response to the challenges of these gameful learning approaches, there is growing interest in the sector in more general playful approaches to learning and teaching, underpinned by playfulness as "a way of engaging with particular contexts and objects that is similar to play but respects the purposes and goals of that object or context” (Sicart, 2014, p. 21). Play is a fundamental part of human experience and learning, providing the opportunity to practise and explore in a safe environment (Koster, 2005; Rieber, 1996). Being playful can support spontaneous learning, facilitate 
social interaction, develop emotional resilience, stimulate imagination, support problem-solving, reduce stress, and increase happiness (Lieberman, 1977; Proyer, 2013).

While there is a vast literature on the benefits and pedagogies of play in childhood, research into playful learning in adulthood is limited, although there is evidence of the importance of adult play (S. Brown \& Vaughan, 2010). Ways of playing, motivations to play, barriers to play, and effects of play differ enormously from children to adults (Colarusso, 1993): play is a ubiquitous and normal in childhood, but play in adulthood is less well understood, even more so when it comes to being playful in higher education.

In order to provide a theoretical lens for playful learning in higher education, we explore a dominant metaphor within the field of game studies, namely the 'magic circle', which contributes to our framing of playful learning as a signature pedagogy. The 'magic circle’ was first posited by play theorist Huizinga (1955), and later applied by game design theorists Salen and Zimmerman (2004) to explain how people construct realities and relationships during play. It denotes a (physical or imaginary) play space that is separate from the real world and mutually-constructed by those within and around it. As a boundary, the circle demarcates a space of safety, where the rules of the real world do not necessarily apply and the internal mechanisms and experiences of play can emerge. They are characterized by different norms and codes of practice, where free experimentation with stereotypical rules of behaviour, belief, or interaction is possible.

Rather than viewing the magic circle as a concrete demarcated space (Salen \& Zimmerman, 2004), we consider it as a socially-constructed liminal space created during play. As such stepping into a magic circle through being playful is a "step outside mundane reality, yet exists in continuity with it and has the capacity to facilitate 
significant social and cognitive changes” (Harviainen, 2012, p. 508). Viewing the magic circle as a "fuzzy social process” (Remmele \& Whitton, 2014, p. 121) points to a key factor here; namely that the magic circle is based on an implicit or explicit agreement to be playful between those who participate. Accordingly, in order for such spaces to exist, a 'lusory attitude' is required (Suits, 1978). That is, the willingness to accept the normal systems of logic or ethics may not apply, as temporary new ones, pertaining to the magic circle at hand, replace them.

Adopting a lusory attitude, is then, we argue, the ability to give oneself over to the experience of playfulness and accepting the immersion in the playful experience with a spirit of sacred rather than profane enjoyment, allowing oneself the freedom to be playful and, subsequently, the freedom to fail at achieving ones lusory goals. This is a shared mind-set that participants accept as they cross the virtual boundary into an imaginary and imaginative space of playfulness, where interactions and experiences emerge through exploration of freedom and control within the magic circle. As a liminal space between the rule-bound and the free-form (Nørgård \& Paaskesen, 2016), the magic circle is as a sacred place where teachers and learners transcend the managerialism and consumerism of higher education and set out to imagine and create manifold ways of being, doing, and knowing in the world through playful attitudes and approaches. Here learners and teachers immerse themselves in the 'what might be' and 'how might we' of higher education by adopting lusory attitudes and engaging in playful open-ended experimentation and exploration in the safe space of the magic circle.

This framing of the concept of the magic circle is both interesting and promising for education as it allows safe spaces for imagining a different type of learning environment in which making mistakes, experimenting, and exploring is not only 
encouraged, but is necessary in order for competency to emerge (Remmele \& Whitton, 2014). Such a framing allows for an educational liminal space within higher education; a space for improvisatory and risky play with worlds and alternative framings; a space where active, ideational, and explorative experiences can take place (Whitton, 2014).

However, this consideration of the theoretical lens of the magic circle as a way of framing an ideology of playful learning does not explain how such philosophies might be implemented in practice, or in itself create a coherent model of playful learning. In the following section, we draw on findings from two research studies on learner experiences in higher education, which we then synthesise with the above theoretical context to develop a signature pedagogy of playful learning in higher education.

\section{Research on the student experience}

Here we present the findings from two studies carried out at Manchester Metropolitan University (MMU) into aspects of student enjoyment and engagement. Study 1, funded by JISC, explored learner perceptions of fun and enjoyment (Bird, Forsyth, \& Whitton, 2012) and Study 2, funded by the MMU Centre for Excellence in Learning and Teaching, examined reasons for learner disengagement with learning opportunities (Langan \& Whitton, 2016). These studies contribute to our understanding of how to create learning experiences that are enjoyable and engaging, and underpin our model of playful learning.

We assume reality is a social construct and understandings of the world cannot be objective, but that individuals create personal meanings and perceptions (Cooper, 1993), and it is the role of the researcher to make sense of these multiple perspectives through interpretive analysis to reach a subjective sense of the area of study. Therefore, 
both studies focused on students’ perceptions of their learning experiences, underpinned by a qualitative approach based on in-depth interviews (Study $1 n=39$; Study $2 n=47$ ). In both studies thematic analyses (Attride-Stirling, 2001; Braun \& Clarke, 2006) were used to identify the key features and similarities of the body of interview data. Participants in Study 1 were recruited via the institution's student jobs service, which enabled straightforward recruitment but also inevitably created a biased sample of students who were perhaps already engaging with university life. The sample comprised 18 males and 21 females, with ages ranging from 18 to 37 years. In Study 2, we worked with five student co-researchers to embed a learner perspective throughout the project; we felt that learner responses would be more authentic when disclosed to peers. This sample comprised 26 males and 21 females, with ages ranging from 18 to 50 years. A full ethical analysis of each project, based on the ethical guidelines of BERA (2011), was undertaken before commencement.

\section{Study 1: Factors that make learning enjoyable}

Study 1 focused on identifying factors that students said made learning enjoyable. Five themes emerged from the analysis:

1. Stimulating pedagogy encompasses teaching that is based on real-life problems and experiences, where students can see the value of what is being taught, are actively and physically engaged rather than passively watching, and where activities are novel or surprising.

2. Lecturer engagement highlights the importance of teacher knowledge and passion for teaching, and the ability of a teacher to create friendly and equitable relationships between themselves and their students, moving away from the idea of a lecturer as the deliverer of knowledge to that of a facilitator or co-learner. 
3. Shared experience highlights the importance of the collaborative aspects of learning with others through teamwork and dialogue, and valuing the diversity of background, skills, and opinions in the student community.

4. Safe spaces identifies that enjoyable learning took place in spaces where students feel relaxed and comfortable with fellow students, where risk-taking and failure is encouraged within an atmosphere of playfulness and goodhumour.

5. Low stress highlights the importance of removal of external stress factors that detract from the enjoyment, and are often associated with assessment criteria, through good time management and being in control of learning experiences.

\section{Study 2: Reasons for disengagement with learning}

Study 2 explored the reasons that students disengage with learning opportunities. Four factors were identified that influenced decisions on whether or not to attend classes:

1. Perceived value of the learning experience and, in particular, whether the class offered more than the presentation of information on slides, if it has an explicit link to assessment, or if the content of the session is new and/or challenging.

2. Conflicting priorities were highlighted; the most common was pressure of assessment, particularly when many were due at the same time, but conflicting work schedules and family or caring commitments were also identified.

3. Peer influence was a significant factor for many younger students; some would not attend a class alone because they felt embarrassed or shy, but in other cases peers normalised non-attendance at classes.

4. Accessibility was also a factor in the attendance decisions for many students, particularly in terms of class location and timing. 


\section{A signature pedagogy for playful learning in higher education}

In this section, we use the idea of signature pedagogies to present a model of playful learning in higher education, drawing on key literature, our experiences in the field, and the two research studies described above. Signature pedagogies enable us to look beyond the surface structure of a lecture or class to focus on the deeper structures of teacher and student interaction and experience. In this way, the lens of signature pedagogy helps us to broaden and deepen our understanding of what playful learning might achieve in higher education. The concept of signature pedagogies builds on widely accepted assumptions about what leads to significant learning. They are composed through a backwards design where significant, worthwhile and lasting learning traits are defined, then the validation of these traits are put forward, and then finally teaching and learning activities are constructed that guide students to embody and demonstrate these learning traits (Gurung, Chick, \& Haynie, 2009, p. 4). Shulman (2005) is generally identified as the originator of the term 'signature pedagogies' and he characterizes them as having three dimensions: surface structure; deep structure; and implicit structure.

"First, it has a surface structure, which consists of concrete operational acts of teaching and learning [...] Any signature pedagogy also has a deep structure, a set of assumptions about how best to impart a certain body of knowledge and know-how. And it has an implicit structure, a moral dimension that comprises a set of beliefs about professional attitudes, values, and dispositions”

(Shulman, 2005, pp. 54-55)

These structures come together to constitute the ways students experience the 'doing', 'being' and 'knowing' of a profession through the ways that are taught and learned in higher education. While some researchers (Gurung et al., 2009; Shulman, 
2005) consider signature pedagogies as those that characterizes a particular discipline, others (Horn, 2013; Waern, 2013) conceptualize them as distinctive practice. The notion of a signature pedagogy can therefore be used both as a horizontal lens looking across institutions to find the common traits of a specific profession, or as a vertical lens looking into ways of teaching and learning which have such influence that they may themselves shape disciplines (Horn, 2013). It is using the second interpretation that we present a model for an emergent signature pedagogy for playful learning in higher education. Drawing together results from the two studies described above as well as the works in educational gaming, play, playfulness and higher-order learning in higher education, we present an initial structuring of the interactions and experiences taking place within playful learning in higher education (see Figure 1). The structure of a signature pedagogy is divided into traits associated with the surface layer (the visible operations of teaching and learning), deep structures (the underlying assumptions underpinning teaching and learning) and the implicit structures (the values of teaching and learning). In our model, we posit that the surface structures are those that echo the core elements of games, the deep structures epitomise play, and the implicit structures embody the nature of playfulness. Together, they provide a signature pedagogy for playful learning in higher education. 


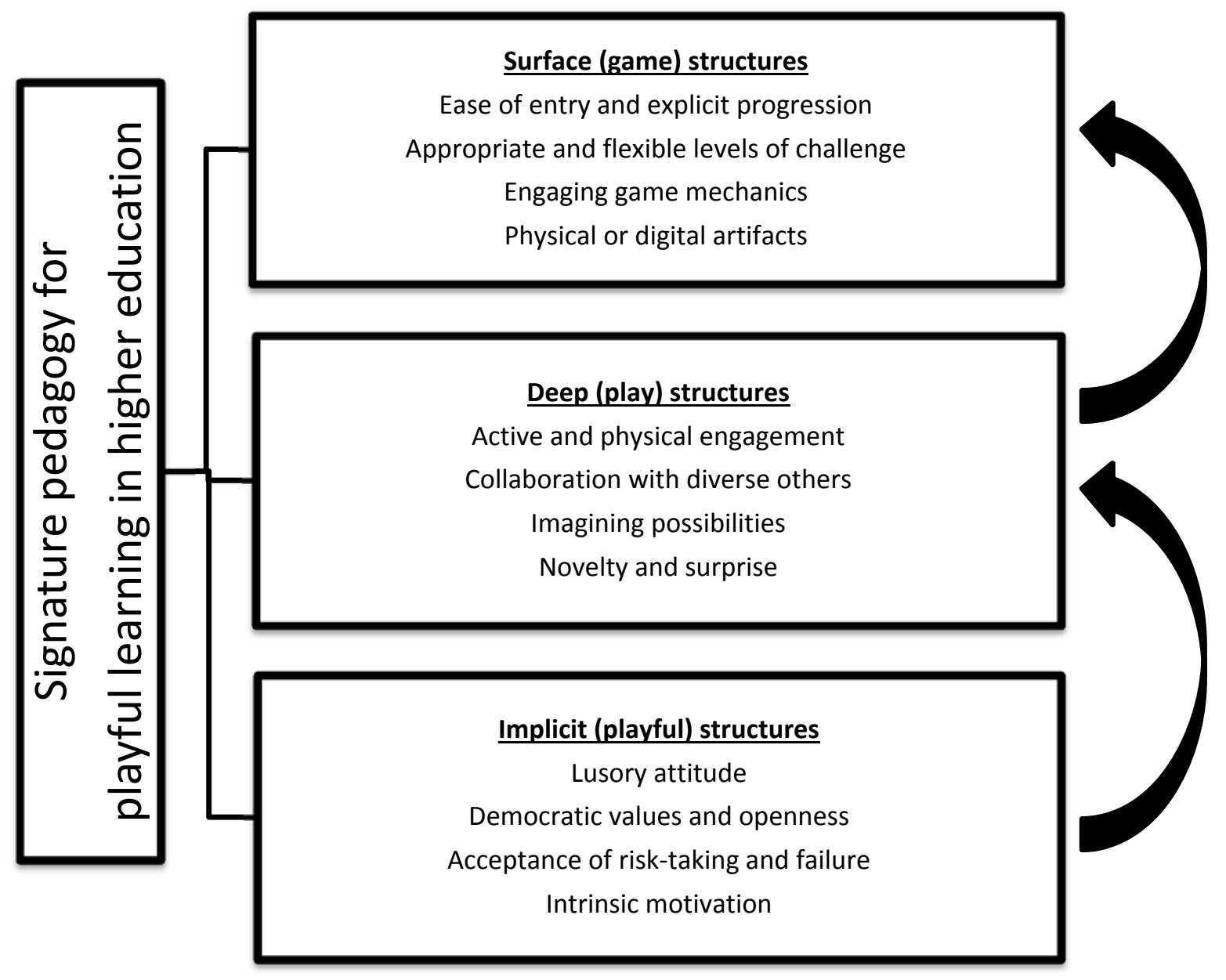

Figure 1: Signature pedagogy for playful learning in higher education

At the surface level, we have highlighted the operational elements of playful learning, drawn from the established practices of gameful learning. Ease of entry into play and learning through supported practice while providing ways of becoming 'unstuck' (Whitton, 2007) helps to create the accessible environment valued by students (Study 2). Appropriate, gradually increasing yet achievable, levels of challenge (Csikszentmihalyi, 1992; Malone, 1980) and use of engaging game mechanics such as visible progression, achievement indicators, and competition (Deterding, 2012), and the 
use of artefacts such as game pieces or cards are recognised approaches in gameful design.

The deep structures of the model highlight the nature of play activities in the signature pedagogy. The elements of active and physical engagement (Study 1/Study 2) and collaborative learning (Study 1) mirror core elements of constructivist learning (Savery \& Duffy, 1995), however the element of novelty and surprise (Study 1) and the imagination of possibilities is distinctly playful and wide-ranging. Imagining possibilities could involve puzzle-solving, telling stories, or creating objects but the common thread is the use of ideation, open-mindedness, and creative thinking to experiment, explore and discoverer unthought-of possibilities (Study 1 and Whitton, 2009).

Finally, we highlight the implicit playful structures, which are primarily drawn from the theoretical lens of the magic circle and necessarily underpin playful learning. A lusory attitude (Suits, 1978) and willingness to enter an imagination space that is separate from the real-world, with passion and enthusiasm from both teachers (Study 2) and students, and a democratic environment of co-learning (Study 1) are essential factors for creating an environment of mutual trust. It is this separateness from the real world (external assessment criteria and grades), and lack of consequences in it (activities of experimenting and exploring), that enables the creation of a space where failure can be viewed as an integral part of the learning paradigm (Study 1), where risktaking and innovation in a safe space are fundamental. The ability to manage failure, both emotionally and practically, increases students' abilities to negotiate risk and develop creative solutions to complex problems. It is by fostering and promoting reflective risk-taking and open-ended engagements with the not-yet-known that learners can explore and experiment with new possibilities and ways of thinking (Nelson \& 
Stolterman, 2012). The intrinsically motivated nature of playful learning is a core underpinning trait, with the activity perceived by learners and teachers as inherently valuable (Study 2).

In this model, the implicit structures (values, habits, ethics) have the strongest presence while the surface structures (materials, tools, actions) have the weakest. That is, signature pedagogies help us move away from the focus on the 'what to' and objects of the learning environment - i.e. games, play artefacts, colourful classrooms and the concrete and operational acts of playing and gaming. This is an important point as it is clear from the pitfalls of gamification and using games in education that the import and implementation of surface structures in higher education alone does not support and promote the attitude and approach of playful learning that we find present in the deep ('how to') and implicit ('why to') structures. As such, the model underlines the fact that signature pedagogies are developed from the implicit pedagogic structures, beginning with the values, habits and ethics we strive for in teaching and learning.

\section{Conclusion}

We have presented an emerging model for a signature pedagogy for playful learning in higher education. We intend this as the basis for discussion, dialogue and reflection rather than a finished product or check-list. We recognise that the two studies described are small scale and represent limited samples of students, but we believe that this analysis is a useful starting point for describing and analysing playful learning as a signature pedagogy.

An inherent paradox of this model is that for many students to view learning as valuable then it must be valued by the system (assessed), yet it is simultaneously this assessment that makes learning stressful and undermines the creation of a safe and 
comfortable environment. In the current higher education climate there will always be a tension between the extrinsic drivers of assessment and the intrinsic desire to learn.

We recognise also that there may be limitations to playful approaches. It is important to remember that not all adults play, and not all are intrinsically playful: some chose not to play, while others are excluded from play. Play is a privilege for those with the time, inclination, appreciation, confidence, social capital, and ability to engage and further research is also needed to explore the implications of the exclusivity of play.

Despite these shortcomings, we believe that playful learning provides a new paradigm for understanding higher education pedagogy in an increasingly performative risk-aversive environment. It is an approach that gives learners and teachers freedom to be playful, freedom to make choices, and freedom towards the world. It is beyond profane seriousness - in the act of being playful, we enrich profane reality by a layer of sacred seriousness. In playful education students not only have to remember and recall information or understand and apply theories - it is even more so the emergence of knowledge through failing, risking, experimenting, wondering, constructing, and critically reflecting. Such approaches carry the potential of circumventing some of the present looming problems within education in general, and disappointments in relation to the promise of gameful and playful approaches in education in specificity. 


\section{References}

Attride-Stirling, J. (2001). Thematic networks: an analytic tool for qualitative research. Qualitative Research, 1(3), 385-405.

Baker, R., Walonoski, J., Heffernan, N., Roll, I., Corbett, A., \& Koedinger, K. (2008). Why Students Engage in “Gaming the System” Behavior in Interactive Learning Environments. Journal of Interactive Learning Research, 19(2), 162-182.

Ball, S. J. (2015). Education, governance and the tyranny of numbers. Journal of Education Policy, 30(June), 299-301.

Bennett, R., \& Kane, S. (2014). Students’ interpretations of the meanings of questionnaire items in the National Student Survey. Quality in Higher Education, 20(2), 129-164.

BERA. 2011. Ethical Guidelines for Educational. British Educational Research Association. London: British Educational Research Association.

Bird, P., Forsyth, R., \& Whitton, N. (2012). Supporting Responsive Curricula Final evaluation report. Bristol. Retrieved from http://www.jisc.ac.uk/media/documents/programmes/curriculumdesign/SRC_Final _Evaluation_Report.pdf

Boyle, E. A., Hainey, T., Connolly, T. M., Gray, G., Earp, J., Ott, M., ... Pereira, J. (2016). An update to the systematic literature review of empirical evidence of the impacts and outcomes of computer games and serious games. Computers and Education, 94, 178-192.

Braun, V., \& Clarke, V. (2006). Using thematic analysis in psychology. Qualitative Research in Psychology, 3(2), 77-101.

Brown, R. (2011). The March of the Market. In M. Molesworth, R. Scullion, \& E. Nixon (Eds.), The Marketisation of Higher Education (pp. 11-24). New York, NY: 
Routledge.

Brown, S., \& Vaughan, C. (2010). Play: How It Shapes the Brain, Opens the Imagination, and Invigorates the Soul. New York, NY: Penguin.

Colarusso, C. A. (1993). Play in Adulthood: A Developmental Consideration. Psychoanalytic Study of the Child, 48, 225-245.

Cooper, P. A. (1993). Paradigm shifts in designed instruction: from behaviorism to cognitivism to constructivism. Educational Technology, 61(3), 12-19.

Csikszentmihalyi, M. (1992). Flow: the classic work on how to achieve happiness. London: Random House.

Deci, E. L., Koestner, R., \& Ryan, R. M. (2001). Extrinsic Rewards and Intrinsic Motivation in Education: Reconsidered Once Again. Review of Educational Research, 71(1), 1-27.

Deterding, S. (2012). Gamification: designing for motivation. Interactions, 19, 14-17.

Dettmer, P. (2005). New blooms in established fields: Four domains of learning and doing. Roeper Review, 28(2), 70-78.

DuBravac, S. (2012). Game mechanics for classroom engagement. Cutting-Edge Technologies in Higher Education, 6 Part C, 67-94.

Frankham, J. (2015). Much Ado about Something The effects of the National Student Survey on Higher Education: An exploratory study. Liverpool.

Gurung, R. A. R., Chick, N. L., \& Haynie, A. (2009). Exploring signature pedagogies : approaches to teaching disciplinary habits of mind. Sterling, VA: Stylus.

Harviainen, J. T. (2012). Ritualistic Games, Boundary Control, and Information Uncertainty. Simulation \& Gaming, 43(4), 506-527.

Hemmi, A., Narumi-Munro, F., Alexander, W., Parker, H., \& Yamauchi, Y. (2014). Coevolution of mobile language learning: Going global with games consoles in higher 
education. British Journal of Educational Technology, 45(2), 356-366.

Horn, J. (2013). Signature pedagogy/powerful pedagogy: The Oxford tutorial system in the humanities. Arts and Humanities in Higher Education, 12(4), 350-366.

Huizinga, J. (1955). Homo Ludens: A Study of the Play Element in Culture. Boston: Beacon Press.

Koster, R. (2005). Theory of Fun for Game Design. Scottsdale, AZ: Paraglyph Press.

Langan, A. M., \& Whitton, N. (2016). Understanding Learner Disengagement: Why do students pay £9,000 a year not to attend lectures? Learning and Teaching in Action, 11(2).

Lieberman, N. (1977). Playfulness: Its Relationship to Imagination and Creativity. New York: Academic Press.

Malone, T. W. (1980). What Makes Things Fun to Learn? Heuristics for Designing Instructional Computer Games. In Proceedings of the 3rd ACM SIGSMALL symposium and the first SIGPC symposium on Small systems (Vol. 162, pp. 162169). New York: ACM.

Mayer, I., Warmelink, H., \& Bekebrede, G. (2013). Learning in a game-based virtual environment: a comparative evaluation in higher education. European Journal of Engineering Education, 38(1), 85-106.

Nelson, H. G., \& Stolterman, E. (2012). The design way: intentional change in an unpredictable world. MIT Press.

Nixon, J. (2008). Towards the virtuous university: The moral bases of academic practice. New York: Routledge.

Nørgård, R. T., \& Paaskesen, R. B. (2016). Open-Ended Education: How Openendedness might foster and promote technological imagination, enterprising and participation in education. Conjunctions: Transdisciplinary Journal of Cultural 
Participation, 3(1), 1-25.

Nørgård, R. T., Smedegaard, S., \& Bengtsen, E. (2016). Academic citizenship beyond the campus: a call for the placeful university. Higher Education Research \& Development, 35(1), 4-16.

Ordorika, I., \& Lloyd, M. (2015). International rankings and the contest for university hegemony. Journal of Education Policy, 30(3), 385-405.

Proyer, R. T. (2013). The well-being of playful adults: Adult playfulness, subjective well-being, physical well-being, and the pursuit of enjoyable activities. The European Journal of Humour Research, 1(1), 84-98.

Remmele, B., \& Whitton, N. (2014). Disrupting the magic circle: the impact of negative social gaming behaviours. In T. M. Connolly, L. Boyle, T. Hainey, G. Baxter, \& P. Moreno-Ger (Eds.), Psychology, Pedagogy and Assessment in Serious Games (pp. 111-126). Hershey, PA: IGI Global.

Rieber, L. (1996). Seriously considering play: Designing interactive learning environments based on the blending of microworlds, simulations, and games. Educational Technology Research and Development, 44(2), 43-58.

Salen, K., \& Zimmerman, E. (2004). Rules of Play: Game Design Fundamentals. Cambridge, MA: The MIT Press.

Savery, J. R., \& Duffy, T. M. (1995). Problem-based learning: an instructional model and its constructivist framework. Educational Technology, 35(5), 135-150.

Shulman, L. S. (2005). Signature pedagogies in the professions. Doedalus, 134(3), 5259.

Sicart, M. (2014). Play matters. Cambridge, MA: MIT Press.

Suits, B. (1978). The Grasshopper: Games, Life and Utopia. Peterborough, Canada: Broadview Press. 
Waern, A. (2013). Game Analysis as a Signature Pedagogy of Game Studies. In Proceedings of Foundations of Digital Games. Chania, Greece.

Whitton, N. (2007). An investigation into the potential of collaborative computer gamebased learning in Higher Education. Edinburgh: Edinburgh Napier University.

Whitton, N. (2009). ARGOSI Evaluation Report. Bristol. Retrieved from http://argosi.playthinklearn.net/evaluation.pdf

Whitton, N. (2011). Digital Games in an age of Austerity. In Proceedings of the 5th European Conference on Games Based Learning (pp. 632-638). Reading: Academic Publishing Limited.

Whitton, N. (2014). Digital Games and Learning: Research and Theory. New York, NY: Routledge. 